\title{
Airway inflammatory and atopy-related responses in athletes
}

\author{
A J McKune (DTech) \\ L L Smith (PhD) \\ Department of Sport and Physical Rehabilitation Sciences, Faculty of Health Sciences, Tshwane University of Technology, Pretoria
}

\begin{abstract}
The prevalence of asthma and airway hyperresponsiveness (AHR) in highly trained endurance athletes is rising. The type of training (i.e. endurance, or speed and power) seems to influence the airway symptoms. High-intensity exercise and training might contribute to the development of asthma or AHR in athletes previously unaffected by these airway disorders. Repeated hyperventilation of unconditioned air, as well as air containing irritants and/or allergens has been suggested to cause thermal, mechanical, or osmotic airway trauma resulting in damage to the airway epithelium. Subsequent airway inflammatory responses may be responsible for the development of atopy-related symptoms in endurance athletes such as those observed in asthma and AHR. Eosinophils and neutrophils are the inflammatory cells that have been frequently observed to be elevated in the airways of endurance athletes. The trafficking of these cells to the airways may possibly be regulated by $\mathrm{T}_{\mathrm{H}} 2$ cytokines that are expressed in the airways in response to epithelial cell damage. In addition, these airway inflammatory responses may lead to airway remodelling similar to that which occurs in asthma. The effect of the exercise challenge itself may initiate airway atopy-related and inflammatory responses in endurance athletes. While the literature seems to support the role of local airway conditions and/or events in inducing atopy-related symptoms in athletes, it is proposed that alterations in the hormonal and/or cytokine milieu with intense competition and/or training may also play a role.
\end{abstract}

\section{CORRESPONDENCE:}

\section{A J McKune}

Department of Sport and Physical Rehabilitation Sciences

Tshwane University of Technology

Private Bag X680

Pretoria

0001

Tel: 012-382 4442

Fax: 012-382 5801

E-mail: mckuneaj@tut.ac.za

\section{Introduction}

Asthma and airway hyperresponsiveness (AHR) are more prevalent in elite athletes compared with sub-elite athletes and the general population. ${ }^{18,35,46}$ Recent observations have suggested that high-intensity exercise and training might contribute to the development of asthma or AHR in athletes previously unaffected by these airway disorders. $7,8,20,24$ The mechanisms explaining the increased prevalence of asthma and AHR remain to be determined. ${ }^{5}$ However, research has suggested that exposure to specific local airway conditions and/or events during training and/or competition may initiate an airway inflammatory response. ${ }^{23}$ Airway inflammation may influence the respiratory system through altering airway function ${ }^{5}$, and possibly inducing airway remodelling, similar to that which occurs in asthma. ${ }^{8}$

This article discusses the recent research regarding asthma, AHR and airway inflammatory responses in athletes. Firstly, an overview of the prevalence of airway symptoms in athletes is provided. Secondly, research examining local airway conditions, events and inflammatory responses is discussed. Thirdly, research examining the possible remodelling of the airways in athletes is reviewed and finally, recommendations for future research in this area are provided.

\section{Prevalence of asthma and AHR in sport}

In the 1976 and 1980 Olympic Games, 9.7\% and 8.5\% of the Australian Olympic athletes had asthma, respectively. ${ }^{12}$ In 1984, $26(4.3 \%)$ of the 597 US Olympic team athletes had asthma, $41(6.9 \%)$ had exercise-induced bronchospasm (EIB), while 42 (7\%) had a history of exercise-induced bronchial symptoms. ${ }^{16}$ Weiler et al. ${ }^{44}$ reported that 107 (15.3\%) of the 699 US Olympic team athletes in the 1996 Summer Olympic Games had asthma. In 1998, the same authors observed a prevalence of $21.9 \%$ in 196 Winter Game Olympic athletes. ${ }^{44}$ From these few studies it seems that the prevalence of atopy-related symptoms is rising in elite athletes.

The type of training (i.e. endurance, or speed and power) seems to influence the airway symptoms (asthma or AHR) in elite athletes. ${ }^{17}$ The prevalence of atopic symptoms is high in endurance sports such as long-distance running (15.5 - $23.9 \%) .^{17}$ It is especially high in cold environment sports such as cross-country skiing (14.4-54.8\%), ${ }^{17}$ as well as in 
swimmers training indoors (13.4 - 44\%). ${ }^{17}$ For speed and power sports, including various athletes such as sprinters, football players and basketball players, the prevalence of asthma is slightly lower and usually ranges from $8 \%$ to $21 \%$. $^{17,23}$

\section{Effect of local airway conditions and events on airway atopy-related symptoms and inflammatory responses}

\section{Dry, cold air}

Exercise hyperventilation with dry, cold air plays an important role in the development of airway symptoms in athletes. ${ }^{23}$ It causes transient dehydration of the bronchial mucosa due to the low water content of the air, leading to a hyperosmolarity of the mucosal fluid of the airway surface lining, which may damage bronchial epithelial cells. ${ }^{1,14}$ The hyperosmolarity of the mucosal fluid alters the osmotic gradient throughout the mucosa and sub-mucosa, resulting in the activation and degranulation of mast cells in the sub-mucosa. Degranulation of these mast cells results in the release of pro-inflammatory mediators and the activation of cholinergic receptors. ${ }^{23}$ This response causes airway smooth-muscle contraction and oedema which together reduce airway function, resulting in atopy-related airway symptoms. ${ }^{1,4}$

It has recently been proposed that eosinophils in the airways become activated via a similar mechanism to that of the mast cells. ${ }^{9}$ Research has indicated that the increased respiratory water loss during prolonged endurance exercise dehydrates the bronchial epithelium. The increased osmolality or osmotic challenge then indirectly triggers the release of eosinophil cationic protein (ECP) from eosinophils, ${ }^{9}$ resulting in further epithelial cell damage, inflammatory responses and consequently airway atopy-related symptoms. ${ }^{9}$ The inflammatory mediators that have been suggested to be implicated during these airway inflammatory responses include histamine, prostaglandins, leukotrienes, and chemotactic factors (chemokines), including IL-8 for neutrophils ${ }^{5}$ and eotaxin for eosinophils. ${ }^{33}$

In contrast to the studies mentioned above, Sue-Chu et al., ${ }^{39}$ found that there were no significant differences in neutrophil or eosinophil counts/activation, but that other inflammatory markers significantly differed between athletes and controls. Examining the effect of hyperventilation of cold, dry air, these authors assessed the degree of macroscopic inflammation, the distribution of inflammatory cells, lymphocyte subtypes and markers of inflammatory cell activation in the airways of 30 adolescent cross-country skiers and 10 non-asthmatic, non-atopic controls. ${ }^{39}$ The airways of these subjects were investigated using bronchoscopy, and inflammatory status was determined through analysing levels in bronchoalveolar lavage fluid (BALF). Nine (30\%) of the skiers were atopic without allergy symptoms. Compared with controls there was a 3-fold increase in airway inflammation in the skiers. They also had greater total cell, percentage lymphocyte and mast cell counts compared with the controls. Neutrophil and eosinophil counts were not significantly different and ECP was not detected. Tumour necrosis factor (TNF)- $\alpha$ and myeloperoxidase were detected in 12 (40\%) and $6(20 \%)$ skiers, respectively. The authors concluded that cross-country skiers have a minor to moderate degree of macroscopic inflammation in the proximal airways compared with normal controls. ${ }^{39}$

Recently, it was reported that exposure to cold air during exercise may up-regulate specific airway cytokine expression that may be responsible for inflammation and atopy-related conditions in the airways of athletes. ${ }^{7}$ Using an animal model (exercising horses) and a random crossover design, BALF was obtained after 15 minutes of submaximal exercise while breathing room temperature or subfreezing air. BALF total and differential nucleated cell counts and relative cytokine mRNA expression in BALF nucleated cells were determined. There were no differences in total or differential cell concentrations between the room temperature and cold air conditions. However, $\mathrm{T}_{\mathrm{H}} 2$ cytokines IL-4, IL-5, and IL-10 were significantly upregulated after cold air exercise 12-, 9-, and 10 -fold respectively compared with warm air exercise. In addition, other cytokines, IL-2 and IL-6, were upregulated to a lesser extent (6- and 3-fold respectively) or not at all (IL-1, IL-8, IFN- $\alpha$, and TNF- $\alpha$ ). The authors argued that exercising while breathing cold dry air induces an overall cytokine pattern in the airways that is predominantly a $\mathrm{T}_{\mathrm{H}} 2$ profile. ${ }^{7} \mathrm{~T}_{\mathrm{H}} 2$ cytokines, in support of the underlying theme of this review, are a characteristic of the systemic immune profile found in allergies and asthma where they regulate the production of $\mathrm{IgE}$ antibodies as well as the infiltration of inflammatory cells such as neutrophils and eosinophils. ${ }^{43}$

\section{Allergens}

Runners, and cyclists are exposed to many pollen allergens in spring and summer. ${ }^{42}$ When the ventilation level exceeds about $30 \mathrm{l} / \mathrm{min}$ there is a shift from nose breathing to combined mouth and nasal breathing. ${ }^{2}$ This shift results in a greater deposition of airborne allergens and other inhaled particles in the lower airways. ${ }^{19}$ Research has demonstrated that symptoms of asthma may develop in athletes who are repeatedly and strongly exposed to pollen allergens. ${ }^{32}$ This author suggested that an allergen overload in the airways could lead to an inflammatory process through an IgEdependent mechanism. In other words, the high number of allergens within the airways could increase the possibility that IgE attached to mast cells become cross-linked. This in turn would lead to an acute inflammatory response through mast cell degranulation and the release of airway pro-inflammatory mediators. ${ }^{23}$

\section{Pollutants}

The quality of the air inhaled by athletes during training or even at rest may contribute to the development of AHR. A relationship has been shown between pollutants such as, 
ozone $\left(\mathrm{O}_{3}\right)$, sulphur dioxide $\left(\mathrm{SO}_{2}\right)$, nitrogen dioxide $\left(\mathrm{NO}_{2}\right)$, exercise and the development of atopy-related respiratory symptoms. ${ }^{23}$ Studies have demonstrated that the combination of exercise and exposure to pollutants can cause a significant increase in bronchoconstriction and a reduction in ventilatory flow when compared with pollution exposure at rest. $^{13,27}$

\section{Swimmers, chlorine and AHR}

Research has found an abnormally high prevalence of AHR among elite swimmers. ${ }^{31}$ Studies have shown that swimmers are chronically exposed to chemical compounds used as water disinfectants. ${ }^{10}$ These disinfectants include chlorine and its derivatives, chloramines and chloroform, which irritate the airways, causing inflammation and oedema of mucous membranes.

Research has shown that during a 2-hour training period, a swimmer may be exposed to an amount of chlorine that exceeds the US recommendation for a worker with 8-hour exposure. ${ }^{10}$ During training and competition, highly trained swimmers inhale large amounts of air that floats just above the water surface, and they may possibly micro-aspirate contaminated water into the trachea and bronchi. ${ }^{16}$ Repeated exposure to chlorine gas has been shown to cause asthma symptoms, airflow obstruction, and increased bronchial responsiveness. ${ }^{6}$ In these cases, the histological analysis of the bronchial mucosa has shown a thickened basement membrane, and eosinophilic inflammation. ${ }^{6}$

A long-term effect of swimming training on airway inflammation was reported by Helenius et al. ${ }^{20}$ These authors investigated respiratory symptoms, increased bronchial responsiveness, and signs of airway inflammation in 29 elite swimmers and 19 healthy controls. The subjects answered a questionnaire and were interviewed for respiratory symptoms. Lung volumes were measured and bronchial responsiveness was assessed by a histamine challenge test. Induced sputum was also collected. Fourteen (48\%) of the swimmers and 3 $(16 \%)$ of the control subjects showed significantly increased bronchial responsiveness. The sputum cell differential counts of eosinophils and neutrophils of swimmers were significantly higher than those of controls. Eosinophilia (sputum differential eosinophil count of $>4 \%$ ) was observed in $6(21 \%)$ of the swimmers and in none of the controls. Symptomatic swimmers had significantly more sputum eosinophils than did those who were symptom-free. The concentrations of sputum eosinophil peroxidase (EPO) and human neutrophil lipocalin ( $\mathrm{HNL}$ ) were significantly higher in swimmers than in control subjects. The authors concluded that long-term and repeated exposure to chlorine compounds in swimming pools during training and competition may contribute to the increased occurrence of bronchial hyperresponsiveness and airway inflammation in swimmers. ${ }^{20}$

\section{Summary of research examining airway inflamma- tion in athletes}

Surprisingly, there are few studies that have addressed the issue of exercise-induced airway inflammatory responses in athletes. In addition to the studies already discussed, a summary of the majority of research available is provided in Table I. Overall, the results indicate that an increase in polymorphonuclear neutrophil (PMN) cells is found in most studies irrespective of the sample type or sport activity, while elevated eosinophil and lymphocyte counts are found mainly in swimmers and skiers. It has been suggested that the elevation in PMNs may be a direct consequence of the endurance exercise, while the elevation in the other cell types may depend on exposure to environmental factors such as chlorine or cold, dry air. ${ }^{4}$ However, this statement is highly speculative and requires additional research. Importantly, the only study examining an underlying mechanism which may explain exercise-induced airway inflammatory responses and the development of atopy-related symptoms has been performed using an animal model. ${ }^{8}$ The results of this study have important implications for understanding the high prevalence of atopy-related airway symptoms in athletes. However, further research on humans is required to verify the findings.

\section{Limited airway inflammatory responses in athletes}

In contrast to the previous discussion regarding airway inflammatory responses inducing atopy-related symptoms in athletes, there is an argument that the airway inflammatory responses are not maladaptive. Research has suggested that similar to systemic compartments, inflammation in the airways is tightly regulated. Recently, it has been argued that the concept of limited systemic inflammation in athletes may also be applicable to the airways. ${ }^{4}$ Although inflammatory cells are recruited to the airways, it has been shown that they do not always become activated. ${ }^{3,25}$ As an example, in swimmers there was significant neutrophil infiltration into the airways, but with no evidence of inflammatory cell activation at rest or after exercise. Specifically, neutrophil elastase concentration in sputum was low at all times. ${ }^{28}$

Preliminary data also suggested that an increase in airway inflammatory cells is not associated with enhanced bronchial responsiveness or functional impairment in nonasthmatic athletes. ${ }^{4}$ Interestingly, research has shown that frequent episodes of exercise hyperventilation may even reduce the susceptibility to bronchoconstriction in welltrained individuals. Specifically, well-trained runners showed blunted responses to metacholine compared with sedentary controls. ${ }^{4}$

Therefore, there may be an inhibitory pathway that prevents or reduces airway inflammatory cell activation and inflammation; however, this has not been identified and further research is required. ${ }^{4}$ Similarly, the questions regarding whether exercise affects the airway and systemic compartments in the same manner, and the possibility that 
training may also cause positive adaptations at the airway level, have not been answered. ${ }^{4}$

\section{Airway remodelling}

Airway remodelling has been shown to occur in atopic disease such as asthma. The process is initiated through chronic airway inflammation and is associated with a continual or abnormal healing process resulting in airway structural alterations. $^{23}$ This remodelling process is characterised by various changes such as hypertrophy and hyperplasia of airway smooth muscle, increased numbers of mucous glands, thickening of the reticular basement membrane from collagen deposition, blood vessel proliferation, and alterations of the extracellular matrix. ${ }^{26}$ These, in turn, lead to airway wall thickening and a permanent reduction in airway calibre with a detrimental effect on respiration. ${ }^{23}$

\section{Airway remodelling in athletes}

There is little information available that links exercise hyperventilation with the induction of structural and/or physiological changes in the airways. ${ }^{23}$ Some preliminary evidence of airway remodelling has been demonstrated in bronchial biopsies from cross-country skiers. ${ }^{21}$

Karjalainen et al. ${ }^{21}$ measured mucosal inflammatory cell infiltration and tenascin expression (a marker of tissue injury) in the sub-epithelial basement membrane in endobronchial biopsy specimens of the proximal airways. The subject populations included 40 elite, competitive skiers without a diagnosis of asthma, 12 subjects (non-athletes) with mild asthma, and 12 healthy controls (non-athletes). Skiers had significantly higher lymphocyte (+43-fold), macrophage (+26fold) and eosinophil (+2-fold) counts compared with healthy controls. Patients with mild asthma also had significantly

TABLE I. Studies on airway inflammatory responses to exercise

\begin{tabular}{|c|c|c|c|}
\hline Author, year (ref) & Athletes tested & Methods & Main results \\
\hline \multicolumn{4}{|l|}{ Cross-country skiers } \\
\hline Sue-Chu et al. $1999^{39}$ & Cross-country skiers & BALF & $\begin{array}{l}\uparrow \text { total cell, lymphocyte, and mast cell counts; markers of inflammatory } \\
\text { cell activation not } \uparrow\end{array}$ \\
\hline Karjalainen et al. $2000^{21}$ & Cross-country skiers & BB & $\begin{array}{l}\text { Compared with controls, } \uparrow \text { T-lymphocytes ( } 43 \text {-fold), macrophages } \\
\text { ( } 26 \text {-fold), eosinophils ( } 2 \text {-fold), PMN ( } 2 \text {-fold) in bronchial mucosa. No } \\
\text { relationship between airway cells and BHR, symptoms or atopy }\end{array}$ \\
\hline Sue-Chu et al. $2000^{38}$ & Cross-country skiers & BALF, BB & $\begin{array}{l}\text { No change in airway inflammation after budesonide treatment } \\
\text { after inhaled steroid ( } 800 \mu \mathrm{g} / \text { day, over } 20 \text { weeks), variable effect on } \\
\text { symptoms treatment }\end{array}$ \\
\hline \multicolumn{4}{|l|}{ Swimmers } \\
\hline Helenius et al. $1998^{18}$ & Elite swimmers & Induced sputum & $\begin{array}{l}\uparrow \mathrm{PMN} \text { and eosinophil differential counts compared with controls; } \\
\uparrow \text { inflammatory markers; eosinophils }=4 \% \text { in } 21 \% \text { of swimmers }\end{array}$ \\
\hline Helenius et al. $2002^{15}$ & Elite swimmers 5-year follow-up & Induced sputum & $\begin{array}{l}\text { Eosinophil differential counts } \uparrow \text { over time in athletes continuing } \\
\text { competitions, decreased in athletes who quit }\end{array}$ \\
\hline Morici et al. $2001^{28}$ & Swimmers training outdoors & Induced sputum & $\begin{array}{l}\text { Baseline: } \uparrow \text { PMN differential counts (swimmers } 44 \pm 22 \% \text {; sedentary } \\
\text { controls: } 10 \pm 6 \% \text { ), no } \uparrow \text { in eosinophils; } 5-\mathrm{km} \text { swimming in outdoor } \\
\text { pool: no change; } 5-\mathrm{km} \text { swimming in the sea (hypertonic environment): } \\
\text { slight } \uparrow \text { in eosinophils }\end{array}$ \\
\hline Boulet et al. $2005^{5}$ & Swimmers training indoors & Induced sputum & $\begin{array}{l}\text { Baseline: no } \uparrow \text { in airway inflammation in high-level swimmers; short- } \\
\text { term high-intensity training }(1 \mathrm{~h}) \text { associated with an } \uparrow \text { in airway } \\
\text { neutrophils in hyperresponsive swimmers }\end{array}$ \\
\hline \multicolumn{4}{|l|}{ Runners } \\
\hline Muns $1993^{29}$ & Half-marathon runners & Nasal lavage & $\begin{array}{l}\text { Post-half-marathon: immediately after } \uparrow \text { PMN (3-fold); } 24 \mathrm{~h} \text { after } \\
\text { remained elevated (1.6-fold) compared with pre-race. } \downarrow \text { in } \% \text { phagocy- } \\
\text { tosing PMNs and function pre-race, immediately after and after } 24 \mathrm{~h}\end{array}$ \\
\hline Muns et al. $1996^{30}$ & Marathon runners & Nasal lavage & $\begin{array}{l}\text { Post-marathon: immediately after } \uparrow \text { PMN }(2.7 \text {-fold); remained elevated } \\
\text { up to } 3 \text { days after. } \uparrow \text { neutrophil chemotactic activity }(2.5 \text {-fold }) \text { immedi- } \\
\text { ately after the race }\end{array}$ \\
\hline Bonsignore et al. $2001^{3}$ & Marathon runners & Induced sputum & $\begin{array}{l}\text { Baseline: } \uparrow \text { PMN differential counts }(79 \pm 9 \%) \text {; post-marathon: further } \\
\uparrow \text { PMN }(91 \pm 4 \% \text { of total cells) }\end{array}$ \\
\hline Wetter et al. $2002^{45}$ & Endurance athletes with AHR & Induced sputum & $\begin{array}{l}\text { Baseline: PMN differential counts: } 37 \% \text { (range } 13-49 \text {, no control sam- } \\
\text { ples); post-exercise: unchanged after placebo or anti-inflammatory } \\
\text { drugs }\end{array}$ \\
\hline Boulet et al. $2005^{5}$ & Marathon runners & Induced sputum & $\begin{array}{l}\text { Baseline: no } \uparrow \text { in airway inflammation in high-level runners; short-term } \\
\text { high-intensity training }(1 \mathrm{~h}) \text { associated with no } \uparrow \text { in airway inflammation }\end{array}$ \\
\hline Davis et al. $2005^{7}$ & Horses & BALF & $\begin{array}{l}\text { Post-15 minutes submaximal exercise. } \uparrow \mathrm{T}_{\mathrm{H}} 2 \text { cytokine (IL-4, IL-5, IL-10) } \\
\text { expression after cold air exercise compared with warm-air exercise }\end{array}$ \\
\hline
\end{tabular}

$\mathrm{BALF}=$ bronchoalveolar lavage fluid; $\mathrm{BB}$ bronchial biopsy; $\mathrm{PMN}=$ polymorphonuclear neutrophil; $\mathrm{BHR}=$ bronchial hyper-reactivity. 
higher lymphocyte $(+70-$ fold), macrophage (+63-fold) and eosinophil (+8-fold) than the controls. In the skiers, neutrophil counts were more than 2 -fold greater than in asthmatic subjects. Tenascin expression was increased in skiers and asthmatic subjects compared with controls. However, the bronchial biopsy findings did not correlate with AHR, atopy or symptoms of asthma. ${ }^{21}$ These authors concluded that prolonged repeated exposure of the airways to inadequately conditioned air may induce inflammation and remodelling in competitive skiers. ${ }^{21}$ It is possible that airway remodelling without airway symptoms may represent a form of adaptation to exercise hyperventilation within the airways. In other words, this may be 'healthy' remodelling rather than maladaptive. Further research is required to test this hypothesis.

However, a recent study, using a canine model, demonstrated that repeated hyperventilation of cold air during exercise may in fact cause airway inflammation and remodelling, leading to asthma-like symptoms. ${ }^{8}$ Daily, repeated hyperventilation caused the influx of eosinophils, neutrophils and mast cells into the airways. Cationic proteins (i.e. ECP) released by the eosinophils were suggested to be partly responsible for airway epithelial cell and connective tissue injury, which was still not healed after 24 hours. This repeated exposure resulted in stratified squamous epithelium (squamous metaplasia), replacing the normal ciliated epithelium. There was also an increase in the thickness of the airway lamina propia (sub-mucosal area) as well as goblet cell hyperplasia, possibly due to oedema relating to damage and an inflammatory response. The increase in squamous epithelium suggested that airway repair and remodelling was taking place. $^{8}$

The loss of airway epithelial cells was shown to be detrimental to normal airway function. These cells are an important source of prostaglandin $\mathrm{E}_{2}\left(\mathrm{PGE}_{2}\right)$, which serves to inhibit cholinergic neurotransmission, smooth-muscle contraction, and mast cell degranulation. ${ }^{22}$ A loss of airway ciliated epithelium and an increase in the thickness of the airway lamina propia result in impaired mucociliary clearance and accumulation of intraluminal debris, leading to the development of airway obstruction. These factors may all play a role in the pathological atopy-related responses of the airways. Davis et al. ${ }^{8}$ concluded that their results suggested that repeated exercise in cold weather could provoke changes in the airway morphology, leading to many of the common symptoms of asthma in athletes who did not previously suffer from this respiratory condition. Although the evidence from this study is convincing, further research is required, specifically using human athletes.

\section{Conclusions and recommendations for future research}

This review has provided a brief discussion of factors that may explain the development of pathological atopy-related responses in athletes. The literature suggests that hyperventilation during exercise, combined with exposure to cold air and/or to a mixture of allergens and pollutants, induces airway inflammatory responses and possibly airway remodelling which may be responsible for the development of asthma or AHR in elite endurance athletes. ${ }^{17}$ The majority of the research has reported differences in inflammatory cell recruitment or activation in the airways of elite endurance athletes, at baseline or after exercise intervention, compared with controls. However, only recently have there been reports of the possible underlying mechanisms that explain the regulation of airway inflammatory responses ${ }^{7}$ and how these airway inflammatory responses may result in pathological airway remodelling. ${ }^{8}$ Importantly, these two studies used animal models and future research should be performed to validate the proposed mechanisms in human studies.

Finally, future research should examine the effect of the exercise challenge itself on airway atopy-related and inflammatory responses in elite endurance athletes. While the literature seems to support the role of local airway conditions and/or events in inducing atopy-related symptoms in athletes, various researchers have proposed that alterations in the hormonal and/or cytokine milieu with intense competition and/or training may also play a role. ${ }^{37,40}$ Specifically, Susuki et al. ${ }^{41}$ have shown that the circulating lymphocyte population is biased toward $\mathrm{T}_{\mathrm{H}} 2$ profile of cytokine secretion after exercise. This bias was related to the concurrent release of glucocorticoids during exercise, which promote a shift from a $T_{H} 1$ to $T_{H} 2$ cytokine profile. ${ }^{11}$ Recently, Smith ${ }^{36,37}$ proposed that the increased incidence of atopyrelated symptoms associated with strenuous exercise may be due to an altered focus of immune function. Specifically, it was hypothesised that repetitive tissue trauma sustained during strenuous exercise training induces a systemic $T_{H} 2$ cytokine profile.

The consequence of the bias towards a $\mathrm{T}_{\mathrm{H}} 2$ profile is the up-regulation of humoral immunity $(\mathrm{HI})$. This implies the proliferation and differentiation of B-cells into antibodysecreting plasma B-cells; immunoglobulin (lg) class (isotype) switching from $\lg M$ to $\lg$ G1-4, $\lg A$ or, in support of the argument in this review, IgE; as well as eosinophil migration from the bone marrow to, and activation in, the airways. ${ }^{33,34}$ As discussed earlier in this review, IgE and eosinophils are crucial factors involved in promoting the airway inflammatory responses that occur in allergies and asthma.

From the above discussion it is feasible to suggest that, in addition to local airway conditions and events, the exercise challenge itself may play a role in influencing atopy-related and inflammatory responses in the airways. Research has yet to determine the exact impact of local and systemic factors on the airway responses of elite endurance athletes and hence, considerably more research is required in this area. 


\section{REFERENCES}

1. Anderson SD, Daviskas E. The mechanism of exercise-induced asthma is... J Allergy Clin Immunol 2000; 106: 453-9.

2. Anderson SD, Togias AG. Dry air and hyperosmolar challenge in asthma and rhinitis. In: Busse WW, Holgate T, eds. Dry Air and Hyperosmolar Challenge in Asthma and Rhinitis. Boston: Blackwell Scientific Publications, 1995: 1178-95.

3. Bonsignore MR, Morici G, Riccobono L, et al. Airway inflammation in nonasthmatic amateur runners. Am J Physiol Lung Cell Mol Physiol 2001; 281: L668-76.

4. Bonsignore MR, Morici G, Vignola AM, et al. Increased airway inflammatory cells in endurance athletes: what do they mean? Clin Exp Allergy 2003; 33: 14-21.

5. Boulet L, Turcotte H, Langdeau J, Bernier M. Lower airway inflammatory response to high-intensity training in athletes. Clin Invest Med 2005; 28: $15-22$

6. Chan-Yeung M, Lam S, Kennedy SM, Frew AJ. Persistent asthma after repeated exposure to high concentrations of gases in pulpmills. Am J Resp Crit Care Med 1994; 149: 1676-80.

7. Davis MS, Malayer JR, Vandeventer L, Royer CM, McKenzie EC, Williamson KK. Cold weather exercise and airway cytokine expression. J App/ Physiol 2005; 98: 2132-6.

8. Davis MS, Schofield B, Freed AN. Repeated peripheral airway hyperapnea causes inflammation and remodeling in dogs. Med Sci Sports Exerc 2003; 35: 608-16.

9. Domej W, Schwaberger G, Tilz GP, et al. Prolonged endurance challenge at moderate altitude. Effect on serum eosinophil cationic protein, eosinophil dynamics, and lung function. Chest 2002; 121: 1111-6.

10. Drobnik F, Freixa A, Casan P, Sanchis J, Guardino X. Assessment of chlorine exposure in swimmers during training. Med Sci Sports Exerc 1996; 28: 271-4.

11. Elenkov IJ. Glucocorticoids and the Th1/Th2 balance. Ann N Y Acad Sci 2004; 1024: 138-46.

12. Fitch KD. Management of allergic Olympic athletes. J Allergy Clin Immunol 1984; 73: 722-7.

13. Folinsbee LJ, Bedi JF, Horvath SM. Pulmonary function changes after 1 hour continuous heavy exercise in $0.21 \mathrm{ppm}$ ozone. J Appl Physiol 1984; 57: 984-8.

14. Freed AN. Experimental models of exercise-induced asthma. In: McFadden ER, ed. Experimental Models of Exercise Induced Asthma. New York: Marcel Dekker, Inc, 1999: 319-49.

15. Helenius H, Rytila P, Sarna $S$, et al. Effect of continuing or finishing highlevel sports on airway inflammation, bronchial hyperresponsiveness, and asthma: A 5-year prospective follow-up study of 42 highly trained swimmers. J Allergy Clin Immunol 2002; 109: 962-8.

16. Helenius I, Haahtela T. Allergy and asthma in elite summer sport athletes. J Allergy Clin Immunol 2000; 106: 444-52.

17. Helenius I, Lumme A, Haahtela T. Asthma, airway inflammation and treatment in elite athletes. Sports Med 2005; 35: 565-74.

18. Helenius IJ, Rytila P, Metso T, Haahtela T, Venge P, Tikkanen O. Respiratory symptoms, bronchial responsiveness, and cellular characteristics of induced sputum in elite swimmers. Allergy 1998; 53: 346-52.

19. Helenius IJ, Tikkanen HO, Haahtela T. Association between type of training and risk of asthma in athletes. Thorax 1997; 52: 157-60.

20. Helenius IJ, Tikkanen HO, Sarna S, Haahtela T. Asthma and increased bronchial responsiveness in elite athletes: Atopy and sport event as risk factors. J Allergy Clin Immunol 1998; 101: 646-52.

21. Karjalainen E, Laitinen A, Sue-chu M, Altraja A, Bjermer L, Laitinen LA Evidence of airway inflammation and remodeling in ski athletes with and without bronchial hyperresponsiveness to metacholine. Am J Respir Crit Care Med 2000; 161: 2086-91

22. Kleeberger SR, Freed AN. Prostanoids. In: Busse WW, Holgate ST, eds Prostanoids. Boston: Blackwell Scientific Publications, 1995: 825-37.

23. Langdeau J, Boulet L. Prevalence and mechanisms of development of asthma and airway hyperresponsiveness in athletes. Sports Med 2001; 31 601-16.
24. Langdeau J, Turcotte H, Bowie DM, Jobin J, Desgagne P, Boulet L. Airway hyperresponsiveness in elite athletes. Am J Respir Crit Care Med 2000 161: $1479-84$.

25. Larsson K, Tornling G, Gavhed D, Muller-Suur C, Palmberg L. Inhalation of cold air increases the number of inflammatory cells in the lungs in healthy subjects. Eur Respir J 1998; 12: 825-30.

26. Lazaar AL, Panettieri RA. Is airway remodeling clinically relevant in asthma? Am J Med 2003; 115: 652-9.

27. Linn WS, Venet TG, Shamoo DA, et al. JD. Respiratory effects of sulphur dioxide in heavily exercising asthmatics. Am Rev Respir Disease 1983; 127: $278-3$

28. Morici GBM, Riccobono L, Insalaco G. Markers of airway inflammation in non-asthmatic swimmers at rest and after exercise. Eur Respir J 2001; 18: $491 \mathrm{~s}$.

29. Muns G. Effect of long-distance running on polymorphonuclear neutrophil phagocytic function of the upper airways. Int J Sports Med 1993; 15: $96-9$.

30. Muns G, Rubinstein I, Singer P. Neutrophil chemotactic activity is increased in nasal secretions of long-distance runners. Int J Sports Med 1996; 17: $56-9$.

31. Potts J. Factors associated with respiratory problems in swimmers. Sports Med 1996; 21: 256-61.

32. Rak S, Bjornson A, Hakanson L, Sorensen S, Venge P. The effect of immunotherapy on eosinophil accumulation and production chemotactic activity in the lung of subjects with asthma during natural pollen exposure. $J \mathrm{Al}$ lergy Clin Immunol 1991; 88: 878-8.

33. Rankin AM, Conroy DM, Williams TJ. Eotaxin and eosinophil recruitment implications for human disease. Mol Med Today 2000; 6: 20-7.

34. Romagnani S. The Th1/Th2 paradigm and allergic disorders. Allergy 1998 53 (suppl. 46): 12-5.

35. Shadick NA, Liang MH, Partridge AJ, et al. The natural history of exerciseinduced anaphylaxis: Survey results from a 10 -year follow-up study. J Allergy Clin Immunol 1999; 104: 123-7.

36. Smith LL. An alternate approach to assessing immune function related to upper respiratory tract infection (URTI). Int Sport Med J 2003; 4: 1-9.

37. Smith LL. Overtraining, excessive exercise, and altered immunity: is this a T helper-1 versus T helper-2 lymphocyte response? Sports Med 2003 33: $347-64$

38. Sue-Chu M, Karjalainen EM, Laitinen A, Larsson L, Laitinen LA, Bjermer L. Placebo-controlled study of inhaled budesonide on indices of airway inflammation in bronchoalveolar lavage fluid and bronchial biopsies in crosscountry skiers. Respiration 2000; 67: 417-25.

39. Sue-Chu M, Larsson L, Moen T, Rennard SI, Bjermer L. Bronchoscopy and bronchoalveolar lavage findings in cross-country skiers with and without "ski asthma". Eur Respir J 1999; 13: 626-32.

40. Suzuki K, Nakaji S, Yamada M, Totsuka M, Sato K, Sugawara K. Systemic inflammatory response to exhaustive exercise. Cytokine kinetics. Exerc Immunol Rev 2002; 8: 6-48.

41. Suzuki K, Yamada M, Kurakake S, et al. Circulating cytokines and hormones with immunosuppressive but neutrophil-priming potentials rise after endurance exercise in humans. Eur J Appl Physiol 2000; 81: 281-7.

42. Tikkanen HO, Helenius I. Asthma in runners. Brit Med J 1994; 309: 1087

43. Umetsu DT, Akbari O, DeKruyff RH. Regulatory T cells control the development of allergic disease and asthma. J Allergy Clin Immunol 2003; 112: 480-7.

44. Weiler JM, Layton T, Hunt M. Asthma in United States Olympic Athletes who participated in the 1996 Summer games. J Allergy Clin Immunol 1998; 102: $722-6$.

45. Wetter TJ, Xiang Z, Sonetti DA, et al. Role of lung inflammatory mediators as a cause of exercise-induced arterial hypoxemia in young athletes. $J$ Appl Physiol 2002; 93: 116-26.

46. Wilber RL. Incidence of asthma and exercise-induced asthma. In: Rundel $\mathrm{KW}$, Wilber RL, Lemanske RF eds. Incidence of Asthma and Exercise-Induced Asthma. Champaign, IL: Human Kinetics, 2002: 39-68. 